\title{
EL PROGRAMA FOGARTY DEL CENTRO INTERDISCIPLINARIO DE ESTUDIOS EN BIOÉTICA
}

La sección central de este número de Acta Bioethica está dedicada a la evaluación de los diez años de operación del programa de ética de la investigación subsidiado por el Fogarty International Center de los National Institutes of Health de Estados Unidos y ejecutado por el Centro Interdisciplinario de Estudios en Bioética (CIEB).

Junto a un documento de evaluación que registra los fundamentos y particularidades del programa y la producción escrita de quienes han sido becarios, se agregan algunos testimonios de alumnos y docentes. En números próximos habrá aún otros testimonios, que agregan la percepción subjetiva de los participantes de lo que ha sido una tarea de indudable impacto en las prácticas de numerosas instituciones. Basta ver la diversidad de nacionalidades, profesiones y funciones de los becarios y de los docentes para percibir la importancia de una iniciativa de esta índole.

No está demás, sin embargo, complementar la información objetiva con algunas observaciones informales. El CIEB recibió en el periodo reseñado tres subsidios (grants), uno para planificación y dos para ejecución de un programa que en sus lineamientos iniciales quería interpelar a tres grupos de destinatarios: científicos latinoamericanos, administradores de instituciones de ciencia y tecnología, y miembros actuales o futuros de comités de ética. A medida que se obtuvo experiencia, este espectro de interesados y destinatarios se matizó, admitiéndose también a personas interesadas en las regulaciones y el basamento jurídico de los procesos de investigación, además de miembros de instituciones académicas que, si bien no practicaban la investigación científica, estaban en contacto con estudiantes que eventualmente podrían ejercerla.

Están descritos los procesos de selección, las tasas de retención del programa y el impacto intelectual e institucional de las actividades. Los protagonistas describen sus expectativas y sus resultados. Pero debe advertirse que en estos años muy pocos fueron los científicos de frontera que pudo reclutarse para esta formación ética. La explicación es simple. Aquellos científicos o médicos involucrados seriamente en la investigación, presionados para publicar y producir, no pueden sustraerse a estas tareas competitivas y demandantes, y dedicarse a las exigencias de un programa como el ejecutado en el CIEB. Éste exigió no solamente trabajo personal antes y después de la fase presencial en la Universidad de Chile, sino lectura y trabajos en áreas que a veces no se encontraban en relación directa con la formación previa. Por otra parte, a tenor de la experiencia de los primeros cursos, la fase presencial en Santiago de Chile se redujo de nueve a tres meses y se reemplazó parte de las actividades por apoyo para realizar acciones educativas y de planificación en el país de origen de los postulantes. En todo momento se dio especial énfasis a la comunicación con el personal académico del programa, a la reflexión sobre la responsabilidad moral en la investigación y a la implementación de planes de estudio que pudieran multiplicar la experiencia.

Muchas de las exigencias docentes parecieron excesivas a los postulantes. Dimos importancia, por ejemplo, a la versación en métodos cualitativos y cuantitativos, porque no puede haber ética en proyectos mal diseñados o pobremente realizados. La dinámica grupal, que tanta importancia reviste en el trabajo de los comités y que tan poca atención recibe en los tratamientos del tema, debió ser modificada para adaptarla a un contexto en que parecía no relevante. Ello constituye un desafío para el futuro, pues nos asiste la convicción de que sin un adecuado conocimiento de los procesos grupales la labor de los comités y comisiones puede quedar, como es habitual, en planos superficiales. Hay en esta materia 
bastante campo para la investigación, que no debe deslizarse hacia una psicologización del trabajo grupal, pero que sería absurdo dejar sin el apoyo de la experiencia de los grupos de entrenamiento o de experiencias interesantes.

La producción escrita de quienes han participado en el programa — tanto docentes como becarios- se encuentra descrita en el artículo que inicia la serie. Es, cuantitativamente, de razonable magnitud. En lo cualitativo debemos señalar que en buena proporción está en castellano. Ello limita su difusión. Por otra parte, muchos autores no se orientaron a la ética de la investigación en sentido estricto e incursionaron en áreas limítrofes, quizá por familiaridad, por comodidad o simplemente por inclinación. La revista Acta Bioethica acogió aquellos productos que, en opinión de los evaluadores externos, cualificaban para ser publicados. Pero mucho de lo que se escribió ha quedado en estado de "literatura gris" no publicada en medios acreditados.

En la sección de Interfaces, que suele recoger artículos remitidos a la revista y no necesariamente relacionados con el tema monográfico principal, tenemos aspectos docentes, reflexiones sobre consentimiento informado y sobre el "ethos" profesional. Estos trabajos cubren un amplio espectro de intereses y motivaciones.

Como es habitual, en este número incluimos comentarios y recensiones de libros.

Fernando Lolas Stepke 